UDC 614.1.

DOI: $10.21668 /$ health.risk/2019.4.04.eng

\title{
SCENARIO ASSESSMENTS OF CLIMATIC WARMING AND POPULATION MORTALITY IN RUSSIAN CITIES LOCATED IN THE SUB-ARCTIC REGIONS IN XXI CENTURY
}

\author{
D.A. Shaposhnikov ${ }^{1}$, B.A. Revich ${ }^{1}$, I.M. Shkol'nik ${ }^{2}$ \\ ${ }^{1}$ The Institute of Economic Forecasting of the Russian Academy of Sciences, 47 Nakhimovskii avenue, Moscow, \\ 117418, Russian Federation \\ ${ }^{2}$ The Voeikov Main Geophysical Observatory, 7 Karbysheva Str., Saint Petersburg, 194021, Russian Federation
}

Climatic changes are the most apparent in the Arctic. Climatic forecasts indicate that warming is continuing on circumpolar territories. There is a vital task to determine attributive fraction of mortality caused by exposure to non-optimal temperatures within the given scenarios. We obtained a dependence of daily mortality on average daily temperatures within a non-linear model with a distributed lag. Daily temperature anomalies that were expected to occur by the middle and the end of the XXI century were calculated as per ensemble calculations of a regional climatic model by Voyekov's Chief Geophysical Observatory; the calculations were made with applying representative trajectories for greenhouse gases concentrations built by the Intergovernmental Expert group on Climatic Change: $R C P_{4.5}$ that led to moderate warming, and $R C P_{8.5}$ that led to the maximum warming. Warming in Russian cities located in the sub-Arctic regions would be accompanied with a general decrease in temperature-dependent mortality. A decrease in cold-induced mortality was more than enough to compensate for an increase in heat-induced mortality for all the examined sub-Arctic territories and warming scenarios. Therefore, the ultimate effect turned out to be quite favorable as mortality caused by all the natural reasons among people older than 30 would decrease by $4.5 \%$ in Murmansk (95\% CI 1.1 - 7.9\%; by 3.1\%, in Arkhangelsk (1.1-5.1\%); and in Yakutsk, by 3.6\% (0.3-7.0\%) by 2090-2099 against 1990-1999 within $R C P_{8.5}$ scenario that involved strong radiation impacts on the climatic system. Expected relative decrease in mortality in Russian Arctic regions could be by several times higher than in the Northern Europe with confidence intervals of obtained assessments being rather similar to each other. These research works complement each other thus indicating that benefits and risks caused by global warming are going to be distributed unevenly.

Key words: climatic changes, climatic warming, climatic models, population mortality, the Arctic, circulatory organs diseases, cerebrovascular diseases, respiratory organs diseases.

It is impossible to imagine climatic scenarios, in spite of all their uncertainties, without concrete numerous assumptions on society development trajectories. Starting from 2014, the Intergovernmental Panel on Climatic Change (IPCC) have been summing these assumptions up and turning them into "representative trajectories for concentrations" of greenhouse gases. This work focuses on two scenarios related to radiation impacts on the climatic system, namely RCP4.5 that results in moderate warming and RCP8.5 that leads to the maximum warming in case there are no meas- ures taken to impose any limitations on greenhouse gases emissions $[1,2]$.

Variable direct and indirect effects produced by climate on population health are most intensely examined on territories where climatic changes are the most apparent or have the greatest amplitude, including Russia. Over 1976-2018 average growth rate for average annual temperature in the Russian Federation amounted to $0.47{ }^{\circ} \mathrm{C} / 10$ years whereas globally temperature growth rate amounted to only $0.17-0.18^{\circ} \mathrm{C} / 10$ years over the same period of time [3]. As our country's territory includes

(C) Shaposhnikov D.A., Revich B.A., Shkol'nik I.M., 2019

Dmitrii A. Shaposhnikov - Candidate of Physical and Mathematical Sciences, senior researcher (e-mail: dshap2014@gmail.com; tel.: +7 (499) 129-18-00; ORCID: https://orcid.org/0000-0001-9191-1974).

Boris A. Revich - Doctor of Medical Sciences, Professor, Head of Laboratory for Environment Quality Prediction and Population Health (e-mail: brevich@yandex.ru; tel.: +7 (499) 129-18-00; ORCID: https://orcid.org/0000-0002-7528-6643).

Igor' M. Shkol'nik - Candidate of Physical and Mathematical Sciences, Leading Researcher and the Head of the Dynamic Meteorology and Climatology Department (e-mail: igor@main.mgo.rssi.ru; tel.: +7 (812) 372-50-33; ORCID: https://orcid.org/0000-0002-7779-0501). 
different climate zones, regional discrepancies in warming forecasts are also significant. We can expect discrepancies also in peculiar effects produced by climatic changes on mortality as it has already been detected in other big countries. For example, in Brazil impacts exerted by warming on mortality become more intense in equatorial regions as compared to those with moderate climate; the greatest growth in additional mortality is predicted in the former ones [4].

Russian Arctic and sub-Arctic territories are expected to experience much more rapid growth in surface temperatures than on average on dry land territories all over the world or in the country. For example, if we compare average annual temperature anomalies over 2000-2009 with 1951-1980, we can see there is a "polar amplification" effect as this anomaly in the Arctic already reaches $2{ }^{\circ} \mathrm{C}$ against global $0.6{ }^{\circ} \mathrm{C}[5]$. Obviously, the phenomenon has occurred primarily due to changes in polar caps albedo caused by ice melting and peculiarities of high altitude jets in the atmosphere [6].

Foreign territories with sub-arctic climate are the northern Scandinavia, the biggest part of Alaska, and Canadian territories located to the north from $50^{\circ}$ n.l. According to the RF legislation, natural and climatic factors are the most significant zoning criteria that are applied when a territory is considered to be a polar one (such territories include Murmansk and Yakutsk) or a territory is assumed to have similar climatic conditions as a polar one (for example, Arkhangelsk), low air temperature being the primary natural and climatic factor. Overall, 8.2 million people or about $5.8 \%$ of the total RF population live on such territories. It is quite natural to expect that climate warming can create certain advantages for all these people, for example, a decrease in number of death cases as local climate will cease to be so harsh, or a growth in agriculture due to a warm season and vegetation period becoming longer ${ }^{1}$.
Our research goal was to quantitatively assess what consequences changes in temperatures on polar territories could have for predicted mortality among population living there; to do that, we had to perform a direct evidential epidemiologic study on influence exerted by temperature on mortality. Such a study is possible only for a compactly living population with a considerable size that has been observed over a sufficient period of time. In other words, it is possible only in cities with their population exceeding 100 thousand people $[7,8]$.

Data and methods. Predictive study layout. In our research we applied conditional predictions of expected changes in average daily temperatures in Murmansk, Yakutsk, and Arkhangelsk in the $21^{\text {st }}$ century; those predictions were obtained via ensemble calculations with a regional climatic model by A.I. Voyekov's Chief Geophysical Observatory of Rosgidromet. This regional climatic model has more significant resolution $(25 \mathrm{~km})$ against global ones and, therefore, is able to provide better insight into meso-scale climate changeability and its contribution into uncertainties in local estimations of future climatic changes. We took 1990-1999 decade as our basic period for a climate forecast; to describe dynamics of expected changes, we took two prediction periods, 2050-2059 (the middle of the $21^{\text {st }}$ century) and 2090-2099 (the end of it). So, we examined two scenarios, RCP4.5 resulting in moderate warming and RCP8.5 leading to the maximum warming, and two prediction horizons for which we calculated expected changes in mortality caused by temperature changes on all days. We applied daily temperature anomalies with a relevant intraensemble standard deviation as our initial data when modeling future changes in mortality. Ensemble included 25 members for RCP4.5 scenario and 50 members for RCP8.5 scenario.

Mortality. Mortality was analyzed as per "climate-dependent" causes of death. 10 mortality parameters were taken into account in

\footnotetext{
${ }^{1}$ The second estimate report given by Rosgidromet on climatic changes and their consequences on the RF territory. The technical summary. Moscow, the Federal Service for Hydrometeorology and Environmental Monitoring, 2014, pp. 69-85. Available at: http://downloads.igce.ru/publications/OD_2_2014/v2014/pdf/resume_teh.pdf (date of visit November 03, 2019).
} 
each city: five groups comprising possible causes of death (all natural reasons, all respiratory organs diseases, all circulatory system diseases with separately analyzed infarctions and strokes) in two age groups (people aged 30-64 and people aged 65 and older). Elderly people aged 65 and older are especially sensitive to changes in temperature caused by warming [9]. Overall number of examined death cases in both age groups is given in Table 1 .

Table 1

Description of initial data applied to model mortality. Minimum and maximum average daily temperatures, internal nods in temperature splines $\left({ }^{\circ} \mathrm{C}\right)$, overall examined number of deaths caused by all natural reasons over 1999-2016

\begin{tabular}{|l|c|c|c|}
\hline City/parameter & Murmansk & Arkhangelsk & Yakutsk \\
\hline$T_{\min }$ & -38 & -37 & -51 \\
\hline$T_{10 \%}$ & -10.9 & -13.3 & -37.9 \\
\hline$T_{75 \%}$ & 8.5 & 10.3 & 12.0 \\
\hline$T_{90 \%}$ & 12.9 & 16.3 & 18.6 \\
\hline$T_{\max }$ & 25 & 27 & 28 \\
\hline \multicolumn{4}{|c|}{$\begin{array}{l}\text { Number of examined deaths caused } \\
\text { by all natural reasons }\end{array}$} \\
\hline $\begin{array}{l}\text { People aged } \\
30-64\end{array}$ & 28,435 & 26,427 & 13,554 \\
\hline $\begin{array}{l}\text { People aged } \\
65+\end{array}$ & 33,137 & 44,213 & 14,597 \\
\hline
\end{tabular}

Temperature curve for mortality and attributive risk. When working out a prediction for additional temperature-dependent mortality, we determined a correlation between everyday mortality and average daily temperatures during the basic period and an optimal temperature in case of which expected mortality is minimal (MMT, minimum mortality temperature). MMT value is a significant property of a population that depends not only on a local climate but also on peculiarities of people who live there (including ethnic ones). In some cities (Norilsk, for example) considerable migration makes determination of this value impossible.

To quantitatively describe impacts exerted by population exposure to non-optimal temperatures, we applied a relative increase in mortality or attributable fraction $(A F)$ and an absolute increase in mortality or attributable number $(A N)$. Both these values measure attributable risk and they have been calculated in this work because $A F$ allows comparing different cities whereas $A N$ gives data on absolute number of deaths in each city (for example, over a year). Attributable risk was determined on a reference day $i$ with temperature $T$ relative to a hypothetical situation should a temperature on this day being equal to MMT:

$$
A F_{T}=1-\exp \left(-\beta_{T}\right) ; A N_{T}=n A F_{T},
$$

where $\beta_{T}$ is a "log-risk" or a logarithm of a relative increase in mortality caused by a temperature rise from MMT to $T$, and $n$ is overall mortality on a reference day $i$; let us give it as Mi under exposure to $T$. This definition can be generalized for delayed dependencies as they exactly occur in our case when average daily temperature in any preset "reference" day exerts its influence on daily mortality in a given city during a finite period with its duration being $L+1$ days ( 1 appears here due to a lag being calculated from a zero day, that is, a reference one). This generalization is obtained via considering a vector of past exposures $T i \ldots T_{i-L}$ and accordingly a "trail" of partial risks $\beta\left(T_{i-l}, l\right)$, $l \in[0 ; L]$ which collectively characterize a delayed impact exerted by temperature on mortality during the overall period. Such generalization was first performed in the work [10] together with suggesting a technique to calculate attributable risk values. Therefore, a risk depends on two variables, namely temperature and lags, so the task is solved via building up a two-dimensional risks surface within a space of possible temperatures and lags. As here we speak about acute effects on health, the maximum possible lag doesn't exceed 2-3 weeks.

\section{A model for mortality with a distributed} lag. To calculate $\beta\left(T_{0}\right) \ldots \beta\left(T_{L}\right)$ values, we applied a non-linear mortality model with a distributed lag [11]. The model has become conventional for examining delayed dependencies between mortality and meteorological parameters and concentrations of pollutants. Our initial data were data on daily mortality provided by the Federal State Statistic Service; the data 
were taken for each examined city and distributed as per causes of death and ages over 1999-2016; we also took meteorological data on average daily temperatures over the same period collected by the All-Russian Scientific Research Institute of Hydrometeorological Information.

Let us determine time series of average daily temperature and mortality over a period during which we model a temperaturedependent component in mortality as vectors consisting of 6,576 (a number of days in 1999-2016) time-ordered observed average daily temperatures $T_{o b s}^{\rightarrow}$ and daily mortality $M_{o b s}$. The first vector is an "exposure vector", and the second one, accordingly, is a "response". In this case, dependence between mortality and temperature taking into account that exposure is delayed and distributed over time is given with a two-dimensional surface $s$ in a space of temperatures and lags:

$$
\begin{gathered}
\log \left[E\left(M_{o b s}^{\vec{b}}\right)\right]= \\
=\alpha+s\left(T_{o b s}^{\rightarrow} ; \theta\right)+f(i ; \beta)+I(d o w ; \gamma) .
\end{gathered}
$$

The equation (2) is supposed to contain Poisson's function for everyday mortality distribution; hence, there is a log-link function, and the rest two summands indicate that mortality apparently depends on time, that is, on a number of day $i$ and a day of the week dow with relevant vectors for regression parameters $\beta$ and $\gamma$. Two-dimensional basis concept is fundamental here as a risk function $s$ is decomposed on it. In case of two-dimensional parameterization the parameter-vector $\theta$ is coefficients for the function $s$ decomposition as per this basis, or tensor product of two onedimensional bases, in a space of temperature and a space of lags. It is necessary to introduce basic functions in order to reduce degrees of freedom in the regression mortality model so that an arbitrary dependence is decomposed as per a finite, and a rather small, set of basic functions. In this case the basis in the space of temperatures was a natural cubic spline with three internal nods that corresponded to specific percentiles in historical distribution of average daily temperatures in each city (Table 1), namely $T_{10 \%}, T_{75 \%}$ and $T_{90 \%}$. Asymmetric choice on the nods $\left(T_{75 \%}\right.$ instead of $\left.T_{50 \%}\right)$ reflects fundamental asymmetry in temperature dependence of mortality. Cubic spline nods in the space of lags were on days 1, 3 and 9 , that is, we chose only three internal nods so that they would be approximately linearly located on the logarithmic time scale with its maximum lag $L=21$ days. This suggestion means that the beginning of the period gives more data on a response in mortality than the end of it.

Attributable risks calculation. The model (2) takes into account all days in the examined period, not only cold or warm seasons; therefore, this model cal allow obtaining estimated values for mortality $\widehat{M}_{i}$ and attributable mortality $\widehat{A N}_{i}$ for all the days in the examined period. If we sum up $\widehat{A N}_{i}$, we get total attributable mortality $\widehat{A N}_{t o t}$ which can be further divided into two summands that correspond to all the days with temperatures being higher than optimal and all the days with temperatures being lower than optimal. These two summands characterize impacts exerted by heat and cold and are given as $\widehat{A N}_{\text {heat }}$ and $\widehat{A N}_{\text {cold }}$. After it, according to the definition (1), we determine attributable fractions for heat and cold:

$$
\widehat{A F}_{\text {cold }}=\frac{\widehat{A N}_{\text {cold }}}{M_{\text {tot }}} ; \widehat{A F}_{\text {heat }}=\frac{\widehat{A N}_{\text {heat }}}{M_{\text {tot }}} \text {. }
$$

A similar calculation can be accomplished for various predicted scenarios for future average daily temperatures $\vec{T}_{f}$, using the same mortality model which is given with the equation (2). The model allows determining "dose - response" function (a dose is a deviation in a temperature from the optimal one, and a response is a relative increase in mortality). As this function is supposed to be invariable during the whole $21^{\text {st }}$ century, model in the equation (4) for future attributable fraction $A F^{f}$ depends only on observed temperatures $T_{o b s}$ :

$$
A F^{f}=
$$

$=\operatorname{attrdl}\left(\vec{T}_{f}\right.$, crossbasis, $\vec{M}_{o b s}$, model $\left.\left(\vec{T}_{o b s} \ldots\right)\right) .(4)$ 
In the equation (4) $\vec{T}_{f}=\vec{T}_{o b s}+\Delta \vec{T}, \Delta \vec{T}$ there is a vector for daily temperature anomalies, a periodical function with its period being equal to 1 year (Figure 1) during the prediction decade; "..." mean other parameters in the model (2); crossbasis is a two-dimensional basis as per which risk surface $\beta\left(T_{i-l}, l\right)$, is decomposed; this basis is obtained via direct (Cartesian) multiplying of two one-dimensional bases in the spaces of temperatures and lags. User function attrdl.R applied to calculate attributable risks in $\mathrm{R}$ was developed for $\mathrm{R}$-package $d \operatorname{lnm} 2.2 .0$ and is available in online application to the work [10].

Building up confidence intervals for attributable risk. Since relative precision of climatic prediction remains several times (5-6) higher in all scenarios and prediction horizons than precision of $A F$ and $A N$ basic estimations, we can approximately calculate ultimate confidence intervals for predictive estimates in two steps. At the first step, three temperature scenarios are created on the basis of a preset emission scenario; they correspond to the central estimate and upper and bottom limits of confidence intervals for predicated average daily temperatures. Attributable numbers of death cases $A N$ and fractions $A F$ are calculated for each of these temperature scenarios. Let us give these fractions as $A F^{f}\left(T_{\text {l.b. }}\right), A F^{f}\left(T_{\text {mean }}\right)$, $A F^{f}\left(T_{\text {u.b. }}\right)$. Here 1.b. and u.b. stay for an upper and bottom limit of $95 \%$ confidence interval (CI) for predicted temperatures, $T_{\text {mean }}$ stays for the central estimate for each day. Each attributable function is calculated with its own confidence intervals. At the second step, the ultimate confidence intervals for $A N$ and $A F$ are constructed; these intervals take into account both errors (in a climatic model and an epidemiologic one). The bottom limit of the ultimate CI is chosen out of minimum three bottom limits of confidence intervals around $A F^{f}\left(T_{\text {l.b. }}\right), A F^{f}\left(T_{\text {mean }}\right), A F^{f}\left(T_{\text {u.b. }}\right)$. Similarly, the ultimate upper limit of the confidence interval for $A F^{f}$ is chosen as a maximum out of three upper limits of the same confidence intervals. This assumption is conservative as it combines confidence intervals of results obtained via two independent model calculations and it re- sults in ultimate confidence intervals being insignificantly wider than they should be. Insignificance of this discrepancy with true confidence intervals around prediction estimates $A F^{f}$ is provided exactly due to a considerable difference between uncertainties of climatic and epidemiologic models.
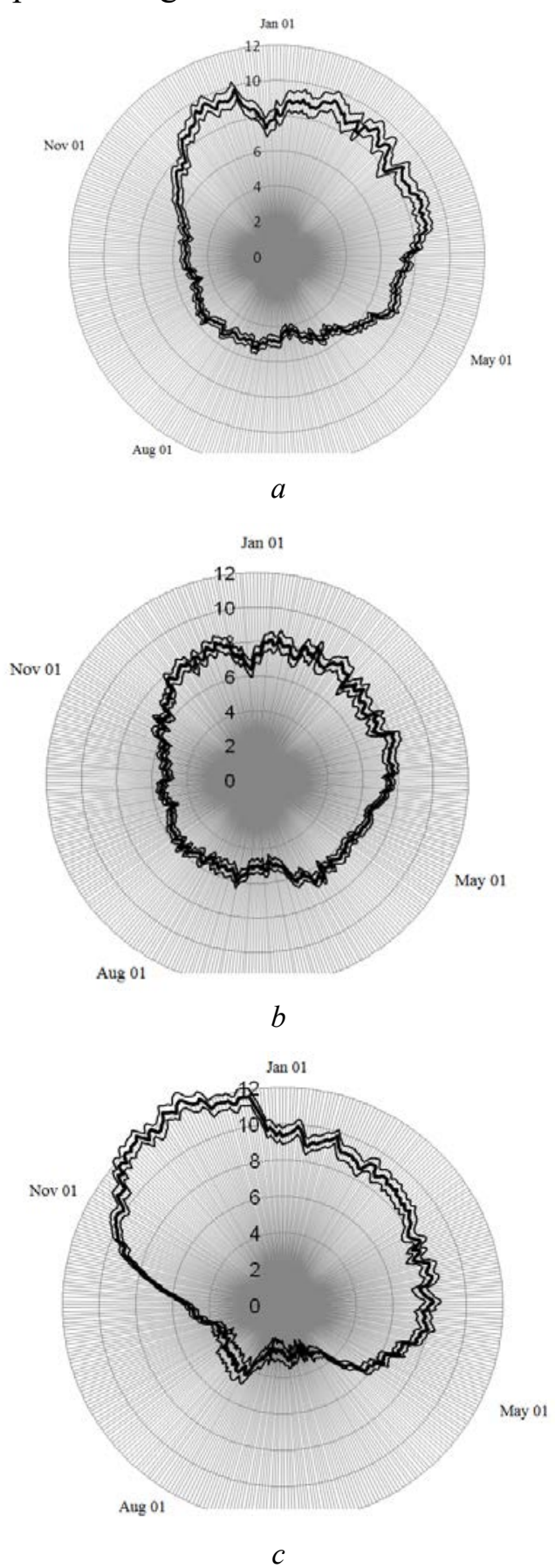

Figure 1. Daily temperature anomalies, a forecast for 2090-2099 against 1990-1999, RCP8.5 scenario. Thick line shows an average estimation, thin lines show 95\% CI limits. Vertical axis shows temperature in ${ }^{\circ} \mathrm{C}$; a) for Arkhangelsk, b) for Murmansk, c) for Yakutsk 
Results. A temperature rise is predicted in all three examined cities all year round and it will be almost linear in time, that is, by the end of the $21^{\text {st }}$ century temperatures will grow by approximately two time more than by the middle of it. Temperature anomalies are apparently seasonal. Figure 1 shows maximum warming under the most aggressive scenario of radiation exposure $\mathrm{RCP}_{8.5}$ by the end of the century. To make comparisons between cities easier, all three diagrams in this Figure are given in the same scale. An order in which cities are located moving from sea climate to continental one corresponds to a growth in winter anomalies. Predicted winter warming in Murmansk is smaller than in Arkhangelsk as $\mathrm{T}$ anomaly is equal to about $+8{ }^{\circ} \mathrm{C}$ in Murmansk and to more than $+9{ }^{\circ} \mathrm{C}$ in Arkhangelsk. Summer temperature anomalies are almost the same in these two cities and are approximately $+5{ }^{\circ} \mathrm{C}$. In Yakutsk warming is even more season-dependent as a difference between summer and winter temperature anomalies is almost four times under the same emissions scenario; in summer it will get warmer by $3{ }^{\circ} \mathrm{C}$, but in November and December temperatures will rise by $12{ }^{\circ} \mathrm{C}$. Under "moderate" radiation exposure scenario $\mathrm{RCP}_{4.5}$ warming amplitude will approximately be two times lower. Let us draw your attention to the extremely narrow confidence intervals around central estimates in temperature anomalies. For example, in Arkhangelsk a relative standard error in predicted temperature anomalies varies from $1.5 \%$ in April to $3.5 \%$ in mid-summer and mid-winter for the scenario shown in Figure 1.

Baseline of temperature-dependent mortality. We calculated population attributable fraction of mortality and attributable number of death cases separately for all days with average temperatures being lower than optimal $\left(A F_{\text {cold }}\right)$ and higher than optimal $\left(A F_{\text {heat }}\right)$ as per the formulas (3) for those mortality parameters for which we established a typical U-like dependence of mortality on temperature. As a time series for everyday mortality $\vec{M}_{o b s}$ is a random function, we can determine this dependence only provided that an initial sampling for assessing mortality has sufficient sta- tistical power. For example, we couldn't establish this dependence in any of three examined cities for mortality caused by cerebrovascular diseases (strokes) among people aged 30-64 due to a small number of such death cases. Naturally, authenticity of AF assessments is influenced not only by statistical power of a sampling but also by a sensitivity of mortality itself to changes in temperature as well as by local climate and local population's peculiarities. For example, there is a peculiarity in Yakutsk as its population has been growing fast; over the examined period it has increased from 195 thousand in 1999 to 304 thousand in 2016. Despite population number being quite comparable in Arkhangelsk, Murmansk, and Yakutsk (348, 316 and 250 thousand in 2007 , the middle of the period considered in the basic model), a number of examined death cases was more than 2 times lower in Yakutsk (Table 1). It probably became a reason for a small number of authentic results obtained via risk assessment in this city. In Arkhangelsk ten examined mortality parameters allowed obtaining eight authentic (0.05) AF assessments (six for cold and two for heat); in Murmansk, four (three for cold and one for heat); in Yakutsk, only one (for cold). This result already allows us to stress that cold produces greater effects on mortality in all cities as well as that local peculiarities also have considerable influence.

Comparison between absolute values of basic $A F_{\text {cold }}$ and $A F_{\text {heat }}$ assessments which we obtained in our work is the most informative for those mortality parameters for which both assessments were statistically significant. It is possible only for two parameters, namely mortality caused by strokes and all circulatory system diseases in Arkhangelsk among people aged 65 and older. For the first of them, $A F_{\text {cold }}=0.240 ; A F_{\text {heat }}=0.010$; that is $A F_{\text {cold }}$ value is 24 times higher than $A F_{\text {heat }}$ value; for the second, $A F_{\text {cold }}=0.236 ; A F_{\text {heat }}=0.007$; that is, $A F_{\text {cold }}$ value is 34 times higher than $A F_{\text {heat }}$ value. Such a discrepancy between these values allows us to assume that future changes $\triangle A F_{\text {cold }}$ will also be higher than $\triangle A F_{\text {heat }}$ in their absolute value as warming increases. This discrepancy is probably due to both 
Table 2

Minimum mortality temperature (MMT), ${ }^{\circ} \mathrm{C}$ and percentile of long-term average daily temperatures distribution

\begin{tabular}{|c|c|c|c|c|c|c|c|}
\hline \multirow{2}{*}{ Age } & City & \multicolumn{2}{|c|}{ Murmansk } & \multicolumn{2}{|c|}{ Arkhangelsk } & \multicolumn{2}{|c|}{ Yakutsk } \\
\hline & Cause of death & ${ }^{\circ} \mathrm{C}$ & percentile & ${ }^{\circ} \mathrm{C}$ & percentile & ${ }^{\circ} \mathrm{C}$ & percentile \\
\hline \multirow{5}{*}{$\begin{array}{l}\text { Jे } \\
0 \\
0\end{array}$} & IHD & - & - & 17.1 & 92 & $25.0^{*}$ & 99 \\
\hline & CVD & - & - & - & - & - & - \\
\hline & CSD & - & - & 18.0 & 93 & - & - \\
\hline & ROD & - & - & 16.9 & 91 & 17.3 & 87 \\
\hline & Natural & 12.4 & 89 & 17.1 & 92 & - & - \\
\hline \multirow{5}{*}{$\stackrel{+}{b}$} & IHD & 16.4 & 96 & 17.5 & 92 & 16.2 & 85 \\
\hline & CVD & - & - & 16.1 & 90 & - & - \\
\hline & CSD & 17.7 & 98 & 16.6 & 91 & 19.5 & 92 \\
\hline & ROD & 12.8 & 90 & $11.3^{*}$ & 77 & 17.8 & 88 \\
\hline & Natural & 14.8 & 94 & 16.6 & 91 & 18.8 & 90 \\
\hline & Mean value & 14,8 & 93 & 17.0 & 91 & 17.9 & 88 \\
\hline
\end{tabular}

Note: * means outliers. Mean values are calculated without them.

IHD is ischemic heart disease;

CVD are cerebrovascular diseases;

CSD are all circulatory system diseases;

ROD are all respiratory organs diseases;

Natural means all natural reasons.

Dash means a value was not determined.

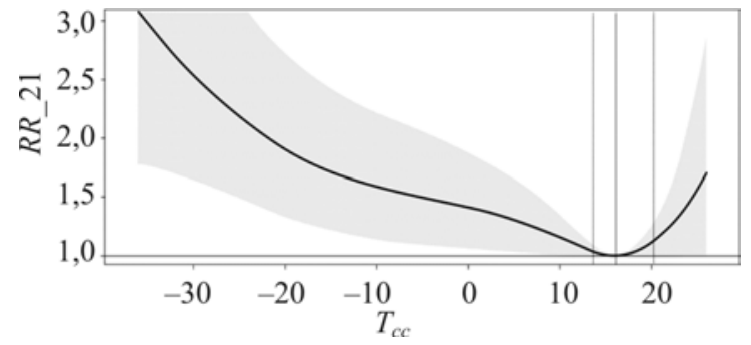

Figure 2. Cumulative relative mortality risk accumulated in a population during 21 days (RR_21) after exposure to average daily temperature $\mathrm{T}_{\mathrm{cc}}\left({ }^{\circ} \mathrm{C}\right)$ obtained in Arkhangelsk for mortality caused by strokes among people aged $65+$. A solid vertical line shows

MMT $\left(+16.1^{\circ} \mathrm{C}\right)$, vertical broken lines show $95 \%$ confidence interval, grey area is confidence intervals of relative risk

different responses people tend to have to cold and heat and to fundamental asymmetry that a temperature curve of mortality has against average annual temperature: MMT corresponds to approximately 90 -th percentile in average daily temperatures distribution. Table 2 contains obtained MMT values both in ${ }^{\circ} \mathrm{C}$ and percentiles of local long-term average daily temperatures distribution. If we compare a temperature curve of mortality to a hockey stick, then its "shaft" is going to be approximately 10 times longer than its "blade" (Figure 2).

As we can see from this table, risk assessment results are more reliable in Arkhangelsk than in two other cities due to MMT values being in a very narrow range there, from $16.1^{\circ} \mathrm{C}$ to $18.0^{\circ} \mathrm{C}$, excluding an outlier marked with the star. In Murmansk MMT values are within a range from $12.4^{\circ} \mathrm{C}$ to $17.7^{\circ} \mathrm{C}$; in Yakutsk, from $16.2^{\circ} \mathrm{C}$ to $19.5^{\circ} \mathrm{C}$. Absolute MMT values grow as a climate on a territory changes from a sea one to continental; on the contrary, relative MMT values, that is, calculated in percentiles from local distributions of average daily temperatures, go down from the 93-th percentile in Murmansk to the 88-th percentile in Yakutsk. This decrease is considerable and is probably due to a type of a climate. For comparison, we can indicate that we applied the same technique to calculate estimate MMT values in Rostov-on-Don and they were detected within a range from $22.7^{\circ} \mathrm{C}$ to $25.5^{\circ} \mathrm{C}$, that is, within a wider range than in Arkhangelsk, with their average value corresponding to the 89 -th percentile [12]. 
In this case average values are not the most probable ones as there are no grounds for assuming that MMT values in a given city should be the same for various mortality parameters. Pathophysiological mechanisms of mortality caused by different reasons also differ; hence, estimate values that are given in Table 2 are taken from different distributions, not from just one. We should also note that some of the examined daily mortality distributions are not statistically independent as CSD comprises IHD and CVD, and CSD account for approximately two thirds of all natural causes.

Predicted dynamics of climate-dependent mortality separately for heat and cold. Attributable fractions $A F_{\text {heat }}$ and $A F_{\text {cold }}$ are given in Figure 3.

To give an example, we took "mortality from infarctions among people aged 65+" though similar patterns were obtained for the rest mortality parameters included into our research. But this very parameter was chosen because we managed to assess relevant fractions for it in all three cities, and the results we obtained in all three cities regarding hot season were quantitatively similar. The Figure 3 clearly illustrates that cold-dependent mortality is considerably higher than heat-dependent one in all three cities and in all warming scenarios. Value of the attributable fraction $A F_{\text {heat }}$ grows as a climate changes from a sea one to continental as a basic $A F_{\text {heat }}^{b}$ estimate has increased from $0.2 \%$ in Murmansk to $0.4 \%$ in
Arkhangelsk and to $1.9 \%$ in Yakutsk. And there is a growth in not only absolute $A F_{\text {heat }}$, values but also in their changes in different decades. To provide a better insight into these changes, let us give some comments, for example, on the last three columns that correspond to $\mathrm{RCP}_{8.5}$ scenario in Yakutsk. In the $21^{\text {st }}$ century $A F_{\text {heat }}$ will grow from $1.9 \%$ to $4.3 \%$, that is, by $2.4 \%$. Simultaneously, $A F_{\text {cold }}$ will fall from c $33.6 \%$ to $26.3 \%$, that is, by $7.3 \%$. Obviously, a decrease in cold-dependent mortality more than compensates for any increase in heat-dependent one for all three cities and for both scenarios. So, a resulting effect is quite favorable as aggregated $A F_{\text {tot }}$ steadily decreases over time. Let us stress that per cent $A F_{\text {cold }}$ and $A F_{\text {heat }}$ values are specially given in the definition (3) in such a way so that they could be directly summed up due to them having the same denominators.

Resulting influence exerted by warming on all the examined mortality parameters is given in Figure 4. Warming-associated changes over time $\triangle A F_{\text {heat }}=A F_{\text {heat }}^{f}-A F_{\text {heat }}^{b}$ and $\Delta A F_{\text {cold }}=A F_{\text {cold }}^{f}-A F_{\text {cold }}^{b}$ will always have a different sign as cold-dependent mortality will fall and heat-dependent one will grow. Their arithmetic sum gives an ultimate change in total temperature-dependent mortality $\triangle A F_{\text {tot }}$ between relevant decades that is given in per cent of the overall mortality in a given city according to the definition (3). It is more convenient to apply attributable fractions $A F$

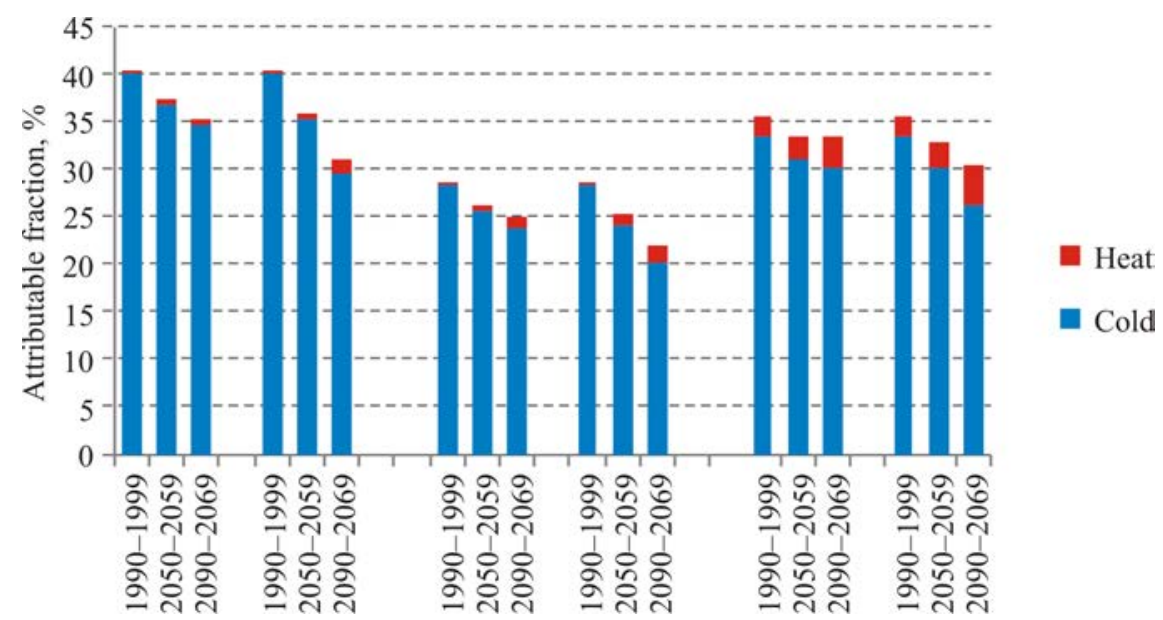

Figure 3. Attributable fractions (\%) for "Mortality caused by infarctions among people aged 65 and older" due to exposure to temperatures being higher than optimal ( $A F_{\text {heat }}$, given in red) and lower than optimal ( $A F_{\text {heat }}$, given in blue). Horizontal axis shows decades applied for predicting 


\section{Arkhangelsk}

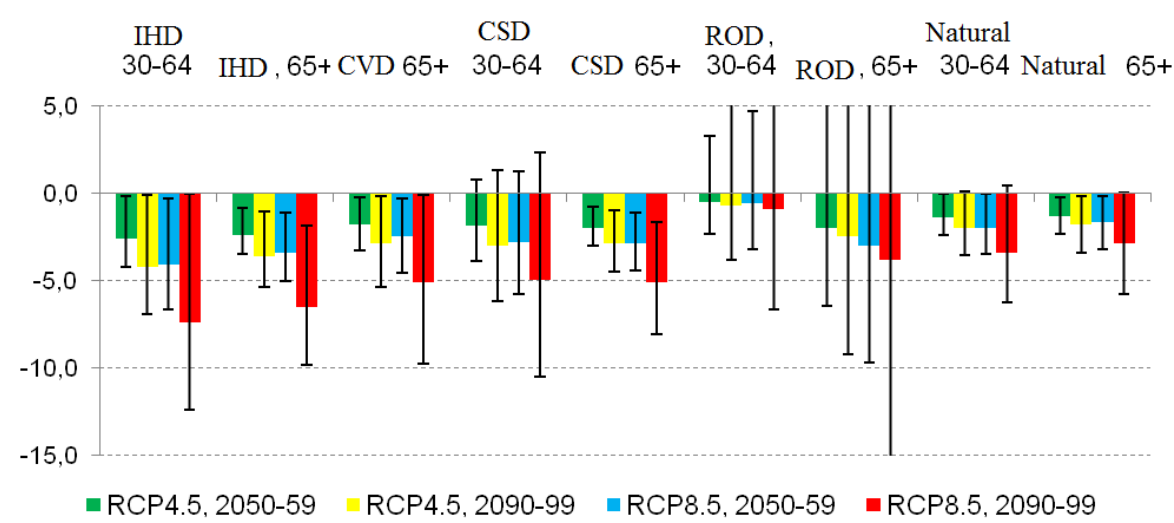

Murmansk

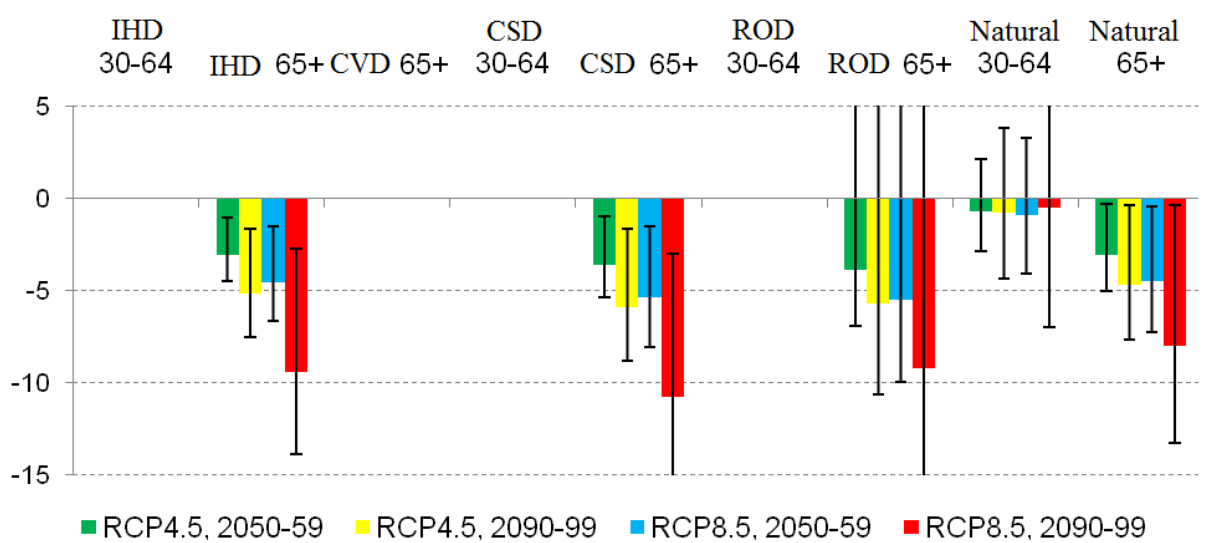

Yakutsk

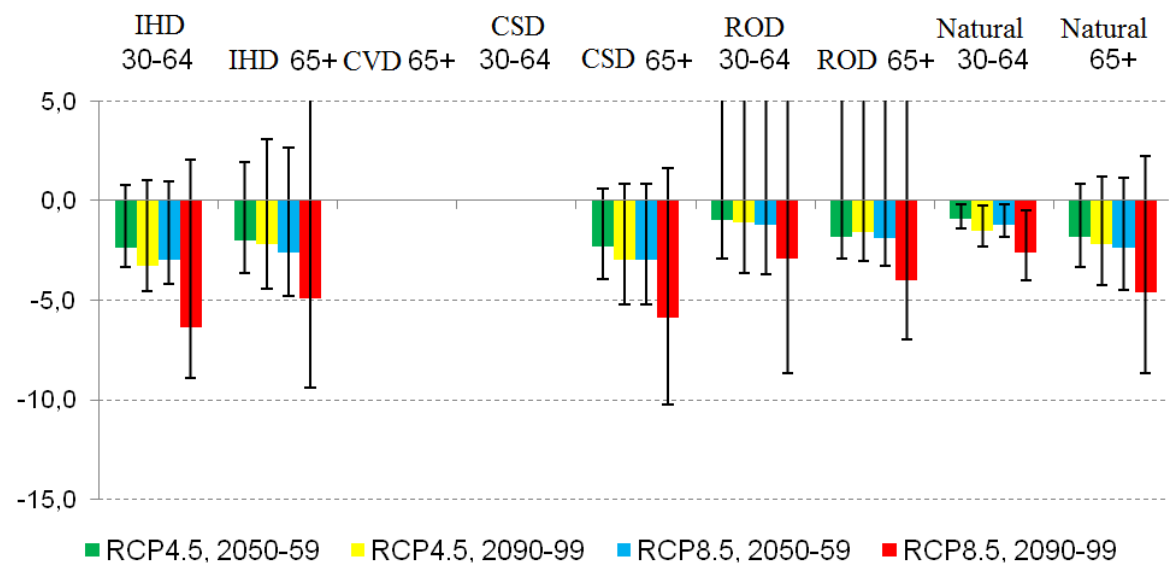

Figure 4. Changes in temperature-dependent mortality against the baseline (1990-1999) predicted by the middle of the $21^{\text {st }}$ century (2050-2059 decade) and by the end of it (2090-2099 decade). $\Delta A F_{\text {tot }}=\Delta A F_{\text {heat }}+\Delta A F_{\text {cold }}$ values show resulting influence exerted by warming an overall decade in percents to the total mortality in the basic period according to the formulas (4). The vertical segments are $95 \%$ confidence intervals of predicted changes. X axis shows the following mortality parameters: IHD is mortality caused by ischemic heart disease or infarctions; CVD is mortality caused by cerebrovascular diseases; CSD is mortality caused by all circulatory system diseases; ROD is mortality caused by respiratory organs diseases; Natural is mortality caused by all natural reasons, external reasons excluded.

The legend also contains data on both scenarios of greenhouse gases emissions, $\mathrm{RCP}_{4.5}$ that results in moderate warming and $\mathrm{RCP}_{8.5}$ that leads to the maximum one. The examined cities are put in such an order that it reflects a change in a climate from a sea one to continental 
(as opposed to attributable numbers $A N$ ) to make comparisons between cities, regions, countries, etc. To make comparisons between the examined cities easier, we drew all the diagrams in Figure 4 in the same scale as per vertical axis.

Relative standard error (RSE) in $A F_{\text {cold }}$ estimate is considerably greater than a standard error in $A F_{\text {heat }}$, estimate, that is, when we calculate a standard error in $\triangle A F_{\text {tot }}$ value, we can completely neglect an error in $A F_{\text {heat }}$ estimate and apply the following approximated correlation:

$$
R S E\left(\triangle A F_{\text {tot }}\right) \approx R S E\left(A F_{\text {cold }}\right)
$$

This correlation is based on the assumption that a change in $\triangle A F_{T}$ fraction is linear as per a $\log$-risk $\beta_{T}$ from the equation (1) at $\beta_{T}<<1$, that is true for any temperature and remains valid till relative precision of temperature anomalies calculations (shown in Figure 1) remains considerably higher than relative precision of basic $A F_{\text {cold }}$ estimate calculation that should be assessed as per confidence intervals of relative risks in Figure 2. Approximated equality (5) allowed avoiding a necessity to empirically calculate confidence intervals of $\triangle A F_{\text {tot }}$ differences in the given situation. Numerical modeling of confidence intervals with Monte Carlo technique is usually applied in such tasks due to $A F^{b}$ and $A F^{f}$ fractions in equation (4) not being statistically independent random values. When calculating confidence intervals as per the formula (5), we took into account their asymmetry as relative error in a parameter $A F_{\text {cold }}$ to the right $\left(R S E_{+}\right)$and to the left $\left(R S E_{-}\right)$can differ greatly; we applied the following correlations:

$$
\begin{aligned}
& \operatorname{RSE}_{-}\left(A F_{\text {cold }}\right) \approx \frac{\mu-l \cdot b .}{2 \mu} ; \\
& R S E_{+}\left(A F_{\text {cold }}\right) \approx \frac{u \cdot b \cdot-\mu}{2 \mu} .
\end{aligned}
$$

This conclusion indicates it is necessary to separately calculate a positive and a negative error in the parameter $\triangle A F_{\text {tot }}$ in Figure 4 , and statistical authenticity of the obtained $\triangle A F_{\text {tot }}$ estimate is determined exactly by $R S E_{-}\left(A F_{\text {cold }}\right)$ value: if in Figure 4 the overall $C I$ is below $\mathrm{X}$ axis, then $\triangle A F_{\text {tot }}$ estimate should be considered authentic. Should CI cross X axis, we can't re- ject a zero hypothesis that there are no effects produced on mortality by warming.

Scenario differences. For both considered warming scenarios, a value of attributable fraction $A F_{\text {tot }}$ continues to decline over time in comparison with the basic period during the whole $21^{\text {st }}$ century with just one exception, namely total mortality caused by all natural reasons in Murmansk among people aged 30-64 within $\mathrm{RCP}_{8.5}$ scenario. For this parameter, by the middle of the $21^{\text {st }}$ century $\triangle A F_{\text {tot }}=-0.9 \%$ $(-4.1 \% ; 3.3 \%)$, and by the end of the century, $\Delta A F_{\text {tot }}=-0.5 \%(-7.0 \% ; 8.0 \%)$. A growth rate for mortality anomalies is exactly equal to growth rate for temperature anomalies in both warming scenarios. Let us explain this statement. According to $\mathrm{RCP}_{4.5}$ scenario, average annual temperature anomaly in Murmansk will reach $\Delta T=2.4{ }^{\circ} \mathrm{C}$ by $2050-2059$ and $\Delta T=3.7^{\circ} \mathrm{C}$ by $2090-2099$ against the basic period. If we divide $\Delta T_{2090-95}$ by $\Delta T_{2050-55}$, we get 1.53. The same value is equal to 1.59 in Arkhangelsk, and to 1.36 in Yakutsk; the average value for all three cities is equal to 1.49. This value can be conditionally called an average growth rate for temperature anomalies over the period between the middle of the $21^{\text {st }}$ century and the end of it. In the same way we can calculate a growth rate for anomaly $A F_{\text {tot, }}$ via dividing $\triangle A F_{2090-95}$ by $\triangle A F_{2050-55}$. For example, the value is $(-5.2 \%) /(-3.1 \%)=1.68$ for "mortality caused by IHD among people aged $65+$ in Murmansk". $\triangle A F_{\text {tot }}$ values are negative, changes in mortality increase as per module over time. We made the same calculation for all mortality parameters in all three cities and then obtained an average estimate and dispersion. We excluded respiratory organs diseases in all three cities and overall mortality caused by natural reasons among people aged 30-64 in Murmansk from our calculations as confidence intervals of $\triangle A F$ estimates obtained for these parameters were too wide. Totally, 15 parameters were included into the calculations, three in Murmansk, seven in Arkhangelsk, and five in Yakutsk. As a result, growth rate for anomalies $A F_{\text {tot }}$ in $\mathrm{RCP}_{4.5}$ scenario over the period between the middle of the $21^{\text {st }}$ century and the end of it amounted to $1.47 \pm 0.17$ and it practically coincides with growth rate for temperature 
anomalies. Let us draw your attention to a very narrow standard deviation in this estimate. For $\mathrm{RCP}_{8.5}$ scenario, corresponding growths are equal to 1.89 for temperature anomalies and $1.91 \pm 0.15$ for $A F_{\text {tot }}$ anomaly, that is, growth rates are again the same. This result is significant as we can expect no "sudden change" in descending mortality trend by the end of the $21^{\text {st }}$ century; annual mortality is expected to decline proportionate to temperature growth for all emissions scenarios.

Age-related differences can be seen among detected effects produced by warming in Figure 4. However, the research layout involved studying an equal number of mortality parameters in both age groups, a number of obtained results turned out to be greater in the older age group in all three cities (it is especially apparent in Murmansk). Effects produced by warming can be estimated as a change in fraction $\triangle A F_{\text {tot }}$ only for those mortality parameters that had an established dependence on temperature (Figure 2). Probably, it was impossible to establish such dependence (provided that a sampling has sufficient statistical power) due to this parameter not being sensitive to temperature changes. But if estimates of effects produced by warming are simultaneously obtained in a given city and for a given death cause in both age groups, then we can expect that an effect in the older group should be greater as per its absolute value than in the younger one. Such pair comparisons can be performed in Murmansk only for a single death cause, namely mortality caused by all natural reasons, excluding external ones; in Arkhangelsk, for all the death causes excluding strokes; in Yakutsk, for infarctions, respiratory organs diseases and all natural reasons excluding external ones. Overall, we can compare eight pairs; the effects were greater in the older age group for five of them; as for the remaining three (IHD in Arkhangelsk and Yakutsk, and all natural causes excluding external ones in Arkhangelsk), the effects were greater in the younger age group.

Geographical differences related to established effects produced by warming are the most interesting within the context of our research. Effects produced by warming were simultaneously detected in all three cities only for five out of ten examined mortality parameters. One out of these five parameters (mortality caused by all natural reasons excluding external ones among people aged 30-64) had outliers in $\triangle A F_{\text {tot }}$ in Murmansk (Figure 4) and was therefore excluded from the analysis; four remaining parameters are given in Table 3.

In Murmansk, effects produced by warming are approximately two times greater as per their absolute value than in two other cities. In Arkhangelsk and Yakutsk effects are comparable as per their value, but effects in Yakutsk as a rule tend to be stronger (for all mortality parameters excluding mortality caused by IHD among people aged $65+$ ).

Table 3

Changes in attributable fractions of temperature-dependent mortality $A F_{\text {tot }}$ in per cent to the baseline: parameters chosen for geographic differences analysis

\begin{tabular}{|c|c|c|c|c|c|}
\hline $\begin{array}{c}\text { Mortality } \\
\text { parameters }\end{array}$ & $\begin{array}{c}\text { Prediction scenarios } \\
\text { and horizons }\end{array}$ & $\begin{array}{c}\text { RCP4.5, } \\
2050-59\end{array}$ & $\begin{array}{c}\text { RCP4.5, } \\
2090-99\end{array}$ & $\begin{array}{c}\text { RCP8.5, } \\
2050-59\end{array}$ & $\begin{array}{c}\text { RCP8.5, } \\
2090-99\end{array}$ \\
\hline \multirow{3}{*}{ IHD, 65+ } & Murmansk & -3.1 & -5.2 & -4.6 & -9.4 \\
\cline { 2 - 6 } & Arkhangelsk & -2.4 & -3.6 & -3.4 & -6.5 \\
\cline { 2 - 6 } & Yakutsk & -2.0 & -2.2 & -2.6 & -4.9 \\
\hline \multirow{3}{*}{ CSD, 65+ } & Murmansk & -3.6 & -5.9 & -5.4 & -10.8 \\
\cline { 2 - 6 } & Arkhangelsk & -2.0 & -2.9 & -2.9 & -5.1 \\
\cline { 2 - 6 } $\begin{array}{c}\text { All reasons } \\
\text { excluding external, } \\
65+\end{array}$ & Yakutsk & -2.3 & -3.0 & -3.0 & -5.9 \\
\cline { 2 - 6 } & Murmansk & -3.1 & -4.7 & -4.5 & -8.0 \\
\cline { 2 - 6 } & Arkhangelsk & -1.3 & -1.8 & -1.7 & -2.9 \\
\hline \multirow{3}{*}{ ROD, 65+ } & Yakutsk & -1.8 & -2.2 & -2.4 & -4.6 \\
\cline { 2 - 6 } & Murmansk & -3.9 & -5.7 & -5.5 & -9.2 \\
\cline { 2 - 6 } & Arkhangelsk & -2.0 & -2.5 & -3.0 & -3.8 \\
\cline { 2 - 6 } & Yakutsk & -1.8 & -1.6 & -1.9 & -4.0 \\
\hline
\end{tabular}


Table 4

Values of attributable mortality caused by all natural reasons reduced to one year, totally for heat and cold (ANtot), number of death cases

\begin{tabular}{|c|c|c|c|c|c|c|}
\hline \multirow{2}{*}{ City } & \multirow{2}{*}{ Age } & Basic & \multicolumn{2}{|c|}{ RCP4.5 } & \multicolumn{2}{c|}{ RCP8.5 } \\
\cline { 3 - 7 } & & $1990-1999$ & $2050-2055$ & $2090-2095$ & $2050-2055$ & $2090-2095$ \\
\hline \multirow{2}{*}{ Murmansk } & $30-64$ & $221(-98 ; 424)$ & $213(-80 ; 408)$ & $214(-49 ; 408)$ & $211(-41 ; 403)$ & $221(-22 ; 392)$ \\
\cline { 2 - 7 } & $65+$ & $434^{*}(53 ; 680)$ & $378^{*}(11 ; 642)$ & $348^{*}(21 ; 578)$ & $352^{*}(25 ; 590)$ & $287^{*}(4 ; 501)$ \\
\hline \multirow{2}{*}{ Arkhangelsk } & $30-64$ & $265^{*}(71 ; 423)$ & $245^{*}(56 ; 387)$ & $235^{*}(64 ; 382)$ & $236^{*}(62 ; 370)$ & $214^{*}(73 ; 343)$ \\
\cline { 2 - 7 } & $65+$ & $373^{*}(104 ; 582)$ & $343^{*}(93 ; 555)$ & $330^{*}(76 ; 528)$ & $330^{*}(77 ; 524)$ & $302^{*}(87 ; 481)$ \\
\hline \multirow{2}{*}{ Yakutsk } & $30-64$ & $323^{*}(29 ; 494)$ & $317^{*}(19 ; 475)$ & $313^{*}(0 ; 476)$ & $315^{*}(0 ; 478)$ & $304^{*}(8 ; 460)$ \\
\cline { 2 - 7 } & $65+$ & $198(-74 ; 348)$ & $183(-97 ; 346)$ & $179(-79 ; 335)$ & $179(-113 ; 331)$ & $161(-113 ; 305)$ \\
\hline
\end{tabular}

Note: * means an estimate is statistically significant at $95 \%$ level.

Attributable numbers of deaths can be significant in certain cases, for example, when it is necessary to economically estimate consequences of warming or take specific managerial decisions. Table 4 contains estimates of $A N_{\text {tot }}$ values in dynamics under various emissions scenarios, but only for all the death causes excluding external ones since this parameter is integral.

Most results given in Table 4 are statistically significant, however confidence intervals are rather wide. An error value is primarily determined by uncertainties related to a descending (that is, induced by cold) section in the temperature curve of mortality (see confidence intervals given in Figure 2). Mortality given in absolute values can decline by just several dozens of death cases per year against the basic level. For example, in Yakutsk according to RCP8.5 scenario that means strong radiation exposure mortality can fall by 56 death cases per year by the end of the $21^{\text {st }}$ century, overall for both age groups.

Discussion. Previous predictive estimates of temperature by 2090-2099 against 2010-2019 [13] according to $\mathrm{RCP}_{8.5}$ scenario give comparatively wide confidence intervals around average weighted estimates of average annual temperature anomalies; they are $4.9^{\circ} \mathrm{C}(3.2-6.3)$ for the North America and $3.4^{\circ} \mathrm{C}(2.8-5.4)$ for the Northern Europe [13] (Table 2). Climate in the North America is continental and, therefore, is closer to sub-arctic zones than that in the Northern Europe. A relative standard error in the prediction is rather great and amounts to $16 \%$ and $19 \%$ respectively. A confidence interval for temperature anomalies predictions that were applied in this work is considerably more narrow as average annual temperature anomalies amount to $5.4{ }^{\circ} \mathrm{C}\left(95 \% \mathrm{CI} 5.0^{\circ} \mathrm{C}-5.7^{\circ} \mathrm{C}\right)$ in Murmansk; $5.6^{\circ} \mathrm{C}\left(5.2^{\circ} \mathrm{C}-.0^{\circ} \mathrm{C}\right)$, in Arkhangelsk; and $5.7^{\circ} \mathrm{C}\left(5.3{ }^{\circ} \mathrm{C}-6.1^{\circ} \mathrm{C}\right)$ in Yakutsk for the same emissions scenarios and the same time periods; that is, RSE is about $3 \%$. We should also note that our central estimates are well in line with temperature anomaly value for the North America which is $4.9^{\circ} \mathrm{C}$.

When predicting future changes in mortality, we assumed that changes occurred only in climatic conditions but temperature dependence of mortality remained the same during the whole $21^{\text {st }}$ century as it was in the basic period of our climatic prediction. This assumption means there is no acclimatization, or individual or population adaptation to climatic changes. But in reality examinations performed on long time series of mortality (during the whole $20^{\text {th }}$ century) show that people adapted to climatic changes that occurred in the $20^{\text {th }}$ century. Thus, MMT value in Stockholm moved to the right as warming persisted, and it was apparent for both its absolute value (in ${ }^{\circ} \mathrm{C}$ ), and its relative one ( as a percentile of average daily temperatures distribution on a day of death). Percentile was calculated over 30-year periods from 1901 to 2009. Over the overall given period, absolute MMT values approximately increased from $11^{\circ} \mathrm{C}$ to $20^{\circ} \mathrm{C}$, and relative ones, from 70-th to 93-th percentile [14], but at the same time average annual temperatures increased by $1.4{ }^{\circ} \mathrm{C}$ only. The same result (on a gradual MMT rise over time) was obtained in France when experts applied data on daily mortality starting from 1968 [15]. There were no 
similar examinations in Russia, and digital data on daily mortality are available only for a period starting from 1999. Bearing this in mind, we can state that our assumption on absence of adaptation which we made in this work can result in an effect being exaggerated in future. To be more exact, we can calculate only an upper limit of a sought effect, or a maximum (as per its absolute value) change in temperaturedependent mortality caused by expected warming. Therefore, it is advisable to not interpret results obtained in the present research as a prediction for changes in climate-dependent component in mortality taking into account all the available scientific data; it is rather a scenario that describes probable consequences that climatic changes night have without taking into account people adapting to them.

Conclusion. Climatic warming will result in a decrease in temperature-dependent mortality in Murmansk, Arkhangelsk, and Yakutsk, and it confirms both results obtained in our previous research [16], and results obtained in global research [13]. Mortality caused by all natural reasons among people aged 30-64 within $\mathrm{RCP}_{8.5}$ scenario that involves strong radiation exposure will fall by $4.5 \%(95 \%$ CI $1.1 \%-7,9 \%)$ in Murmansk, by $3.1 \%(1.1 \%-5.1 \%)$ in Arkhangelsk, and by $3.6 \%(0.3 \%-7.0 \%)$ in Yakutsk by $2090-2099$ against 1990-1999. The same change in mortality within $\mathrm{RCP}_{8.5}$ scenario is also expected by the end of the $21^{\text {st }}$ century in the Northern
Europe: $-0.6 \%$ (95\% CI $-2.3 \%-1.6 \%$ ) [14]. Nevertheless, mortality will increase during heat waves in sub-arctic cities, especially that among elderly people $[8,17,18]$. Mathematic techniques applied to assess influence exerted by such waves on population mortality are described in the work by D.A. Shapochnikov and B.A. Revich [19].

An expected relative decrease in mortality in sub-arctic regions can be several times more considerable than in the Northern Europe, but at the same time confidence intervals of obtained estimates are rather similar. These studies supplement each other thus proving that benefits and risks related to global warming are distributed rather unevenly. Undoubtedly, it is necessary to include scenario assessments of positive and negative consequences caused by climatic changes in various climatic zones in Russia into regional adaptation plans that are to be developed by executive authorities. And here it is important to apply economic parameters related to health losses, for example, in the same way as it was done when assessing consequences caused by abnormal heat in Moscow in 2010 [20].

Finding. The research was provided financial support by the Russian Foundation for Basic Research within the scientific project No. 18-00-00600 (18-00-00596 and 18-00-00599).

Conflict of interests. The authors declare there is no any conflict of interests.

\section{References}

1. Pachauri R.K., Allen M.R., Barros V.R., Broome J., Cramer W., Christ R., Church J.A., Clarke L. [et al.]. Climate Change 2014: Synthesis Report. Contribution of Working Groups I, II and III to the Fifth Assessment Report of the Intergovernmental Panel on Climate Change. In: R.K. Pachauri, L. Meyer eds. Geneva, Switzerland, IPCC Publ., 2014, 151 p.

2. Van Vuuren D.P., Edmonds J.A., Kainuma M., Riahi K., Thomson A.M., Hibbard K., Hurtt G.C., Kram T. [et al.]. The representative concentration pathways: an overview. Climatic Change, 2011, no. 109, pp. 5-31. DOI: $10.1007 / \mathrm{s} 10584-011-0148-\mathrm{z}$

3. Izmeneniya klimata 2018 god (dekabr' 2017 - noyabr' 2018). Obzor sostoyaniya i tendentsii izmeneniya klimata Rossii [Climatic changes in 2018 (December 2017 - November 2018): review of the current situation and trends in climatic changes in Russia]. Moscow, Institut Global'nogo klimata i ekologii imeni akademika Yu.A. Izraelya Rosgidrometa Publ., 2019, 11 p. (in Russian).

4. Vicedo-Cabrera A.M., Guo Y., Sera F., Huber V., Schleussner C.F., Mitchell D., Tong S., Lavigne E. [et al.]. Temperature-related mortality impacts under and beyond Paris Agreement climate change scenarios. Climatic Change, 2018, vol. 150, no. 3-4, pp. 391-402. DOI: 10.1007/s10584-018-2274-3

5. Temperatures are warming faster in the Arctic than anywhere else in the world. Here's why. NASA. Earth Observatory, 2013. Available at: https://earthobservatory.nasa.gov/images/81214/arcticamplification (03.11.2019). 
6. Serreze M., Barry R. Processes and impacts of Arctic amplification: A research synthesis. Global and Planetary Change, 2011, vol. 77, no. 1-2, pp. 85-96. DOI: 10.1016 / j.gloplacha.2011.03.004

7. Shaposhnikov D., Revich B. Toward meta-analysis of impacts of heat and cold waves on mortality in Russian North. Urban Climate, 2016, no. 15, pp. 16-24. DOI: 10.1016/j.uclim.2015.11.007

8. Shkolnik I.M., Efimov S.V. Cyclonic activity in high latitudes as simulated by a regional atmospheric climate model: added value and uncertainties. Environ. Res. Letters, 2013, vol. 8, no. 4, pp. 5007. DOI: $10.1088 / 1748-9326 / 8 / 4 / 045007$

9. Watts N., Amann M., Arnell N., Ayeb-Karlsson S., Belesova K., Boykoff M., Byass P., Cai W. [et al.]. The 2019 report of The Lancet Countdown on health and climate change: ensuring that the health of a child born today is not defined by a changing climate. Lancet, 2019, vol. 394, no. 10211, pp. 1836-1978. DOI: 10.1016/S0140-6736(19)32596-6

10. Gasparrini A., Leone M. Attributable risk from distributed lag models. BMC Medical Research Methodology, 2014, vol. 14, no. 1, pp. 55. DOI: 10.1186/1471-2288-14-55

11. Gasparrini A., Armstrong B., Kenward M.G. Distributed lag non-linear models. Statistics in Medicine, 2010, vol. 29, no. 21, pp. 2224-2234. DOI: 10.1002/sim.3940

12. Shartova N.V., Shaposhnikov D.A., Konstantinov P.I., Revich B.A. Air temperature and mortality: heat thresholds and population vulnerability study in Rostov-on-Don. Fundamental'naya i prikladnaya klimatologiya, 2019, no. 2, pp. 66-94 (in Russian).

13. Gasparrini A., Guo Y., Sera F., Vicedo-Cabrera A.M. Projections of temperature-related excess mortality under climate change scenarios. The Lancet Planetary Health, 2017, vol. 1, no. 9, pp. e360-e367. DOI: $10.1016 / \mathrm{S} 2542-5196(17) 30156-0$

14. Oudin Å.D., Tornevi A., Ebi K.L., Rocklöv J., Forsberg B. Evolution of minimum mortality temperature in Stockholm, Sweden, 1901-2009. Environ Health Perspect, 2016, no. 124, pp. 740-744. DOI: $10.1289 /$ ehp. 1509692

15. Todd N., Valleron A.J. Space-time covariation of mortality with temperature: a systematic study of deaths in France, 1968-2009. Environ Health Perspect, 2015, vol. 123, no. 7, pp. 659-664. DOI: $10.1289 /$ ehp. 1307771

16. Shaposhnikov D., Revich B., Meleshko V., Govorkova V., Pavlova T. Climate change may reduce annual temperature-dependent mortality in subarctic: a case study of Archangelsk, Russian Federation. Environ. Nat. Resour. Res., 2011, no. 1, pp. 75-91. DOI: 10.5539/enrr.v1n1p75

17. Varakina Zh.L., Yurasova E.D., Revich B.A., Shaposhnikov D.A., Vyaz'min A.M. Air temperature impact on mortality in Arkhangelsk in 1999-2008. Ekologiya cheloveka, 2011, no. 6, pp. 28-36 (in Russian).

18. Revich B.A., Shaposhnikov D.A., Anisimov O.A., Belolutskaya M.A. Impact of Temperature Waves on the Health of Residents in cities of the Northwestern Regions of Russia. Studies on Russian Economic Development, 2019, vol. 30, no. 3, pp. 327-333. DOI: 10.1134/S1075700719030158

19. Shaposhnikov D.A., Revich B.A. On some approaches to calculation of health risks caused by temperature waves. Health Risk Analysis, 2018, no. 1, pp. 22-31 (in Russian). DOI: 10.21668/health.risk/2018.1.03.eng

20. Porfir'ev B.N. Economic Evaluation of Human Losses from Disasters. Voprosy ekonomiki, 2013, no. 1, pp. 46-68 (in Russian). DOI: 10.32609/0042-8736-2013-1-48-68

Shaposhnikov D.A., Revich B.A., Shkol'nik I.M. Scenario assessments of climatic warming and population mortality in russian cities located in the sub-arctic regions in XXI century. Health Risk Analysis, 2019, no. 4, pp. 37-49. DOI: 10.21668/health.risk/2019.4.04.eng

Received: 10.10 .2019

Accepted: 01.12 .2019

Published: 30.12.2019 